\title{
Tumor prevalence in cats: experience from a reference diagnostic center in Mexico City (2006-2018)
}

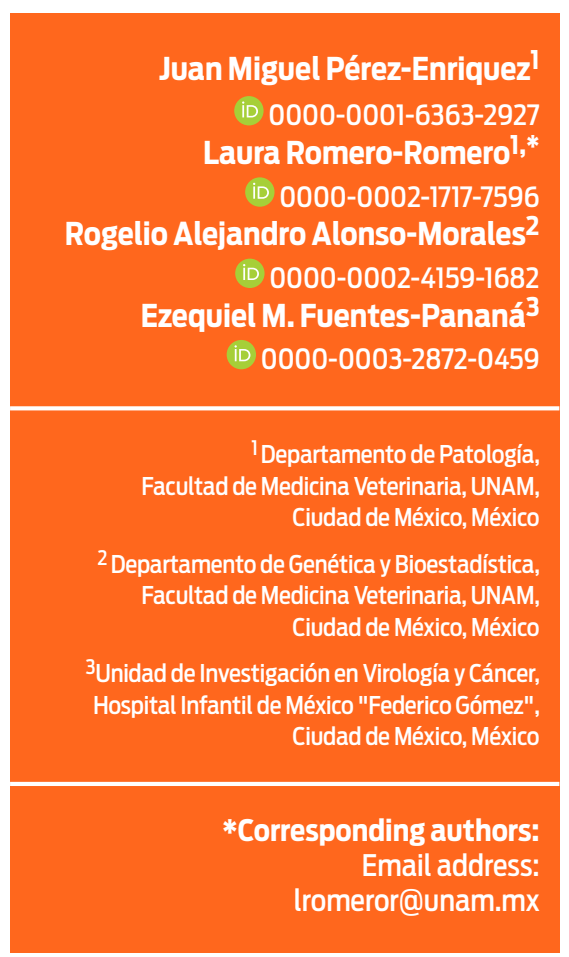

Published: $\quad 2020-12-18$

@ Copyright 2020 Juan Miguel Pérez-Enriquez et al.

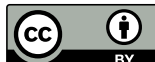

Distributed under Creative Commons CC-BY 4.0

\begin{abstract}
Records of referred cat cases received for diagnosis in the Department of Pathology of the National Autonomous University of Mexico, School of Veterinary Medicine and Animal Husbandry between 2006 and 2018, were reviewed to examine frequency of occurrence of neoplasms and associated demographic factors. To this end, the records of biopsies, necropsies and clinical information were analyzed to obtain data on animal sex and age, as well as neoplasm histotype, tissue of origin, and malignant/benign biological behavior. A total of 685 neoplasm cases were diagnosed during the study period, which represented $37.7 \%$ of all referred histopathological domestic cat cases. Epithelial neoplasms were the most prevalent (56\% of cases), followed by mesenchymal tumors (27\%), and hematopoietic and lymphoreticular neoplasms (17\%). The most common tumor type was carcinoma (31\%), followed by sarcoma (14\%), adenocarcinoma (13\%), lymphoma (13\%), and adenoma (6\%). Squamous cell carcinoma was the most frequent form of carcinoma (117 cases), followed by lymphoma (88 cases), and spindle cell sarcoma (56 cases). Approximately $85 \%$ of all cases corresponded to malignant neoplasms. A relationship between sex and histogenesis was observed, but there was no gender association with malignant behavior. Also, hematopoietic/ lymphoreticular tumors occurred more frequently at an early age, than other types of neoplasms. To the extent of our knowledge, this is the first epidemiological report indicating the most common neoplasms in a Mexican domestic cat population.
\end{abstract}

\section{Cite this as:}

Pérez-Enriquez JM, Romero-Romero L, Alonso-Morales RA, Fuentes-Pananá EM. Tumor prevalence in cats: experience from a reference diagnostic center in Mexico City (2006-2018). Veterinaria México OA. 2020;7(4). doi. 10.22201/fmvz.24486760e.2020.4.837 


\section{Introduction}

Cancer is a common disease and one of the most important causes of death in domestic animals. ${ }^{1}$ Although precise data on the incidence of tumors in dogs and cats is lacking, conservative estimates suggest that one in every ten dogs or cats will develop a tumor during their lifetime. While human cancer records have existed and evolved since 1940, veterinary registers have been brief and sporadic. 2,3,4 One of the oldest accounts, that considers a reference study of many years, is The California Animal Neoplasm Registry, which started in 1963 to identify all diagnosed neoplasms in animals in the San Francisco Bay Area and Alameda and Contra Costa counties. 5,6 At present, different worldwide records exist, showing that cancer is the cause of death in approximately $15-30 \%$ of dog and $26 \%$ of cat populations. However, there are deviations from these numbers depending on the reported period and the geographic region. ${ }^{2}$ One of the largest studies in feline populations was carried out in Switzerland by Graf et al (2015) and reports a 34.79\% of neoplasm cases in cats in a 43-year period (1965-2008). ${ }^{3}$ Another equally relevant report was undertaken in the United Kingdom, analyzing over 9,000 feline cutaneous tumors, where squamous cell, fibrosarcoma and basal cell carcinomas were the most frequent types of neoplasms found between 2006 and 2013. ${ }^{7}$ These registers have paved the way for epidemiological and descriptive studies that have helped us comprehend the severity of this disease for domestic cats.

The objective of the present study was to analyze archival data of cats cases referred to the Department of Pathology of the National Autonomous University of Mexico School of Veterinary Medicine (FMVZ-UNAM), a veterinary diagnostic reference center in the central area of the country. Data were evaluated to determine the most frequently diagnosed feline neoplasms in this cohort, highlighting tumor histogenesis (tissue of origin) and histotype (mainly sarcomas, carcinomas, and lymphomas), as well as a possible association of frequency of presentation with animal age and sex. To the best of our knowledge, there are not systematic registries in Mexican Veterinary centers and/or epidemiological reports regarding the most common neoplasms in Mexican domestic cats.

\section{Materials and methods}

A total of 13 years of records of feline cases referred to the FMVZ-UNAM Pathology Department for histopathological analysis or post-mortem evaluation were examined, from which only tumor-related reports were selected. Data were compiled considering sex and age of cats, as well as histogenesis, and tumor histotype. For histogenesis classification, the type of the tumor cells was considered (polygonal for epithelial, spindle for mesenchymal, and round cells for hematopoietic and lymphoreticular types), according to what has been previously described. ${ }^{8}$ Histotype was also considered (e.g. sarcomas, carcinomas, lymphomas, etc.), in addition to the benign or malignant nature of the lesion. Due to the uneven frequency of mixed breed (domestic shorthair) over purebred cats, this variable was not included in the study. In addition, tumor anatomic location could only be ascertained for lymphomas.

The analysis of histotype frequency was performed on nominal-scale variables, both in absolute and relative numbers (measured as percentages). A contingency 
table was created to assess the association between histogenesis and biological behavior of neoplasms (benign or malignant), using Pearson's chi-square test. ${ }^{9}$ For each tumor histotype, descriptive statistics for age of presentation (in years) were calculated (mean, median, standard deviation, and maximum and minimum values). ${ }^{10,11}$ The Kruskal Wallis test ${ }^{10}$ was used to compare both the histogenesis categories (epithelial, mesenchymal and hematopoietic/lymphoreticular) and the most frequent histotypes. Age was also grouped as kitten $(<7$ months), junior (7 months to 2 years), prime (3-6 years), mature (7-10 years), senior (11-14 years) and geriatric ( $>15$ years), following the American Association of Feline Practitioners-American Animal Hospital Association (AAFP-AAHA) guidelines ${ }^{12}$ for variable comparisons. Odds ratios (OR) were calculated for variables sex and neoplastic behavior (malignant/benign). ${ }^{9} \mathrm{~A}$ p-value $<0.05$ was considered as significant. All statistical analyses were completed using the SPSS v25 program for macOS (IBM).

\section{Results}

From 1,816 cases of domestic cats that where referred for histopathological diagnosis to the FMVZ-UNAM Pathology Department between 2006 and 2018, 685 were neoplasms (37.7\%), 109 of which were diagnosed by necropsy and 576 by biopsy. The frequency of neoplastic cases was constant throughout the study years, with an average of 37\% neoplastic cases by year and a standard deviation of 5 cases between years. The minimum percentage of tumor occurrence was $28 \%$ in 2014 , whilst the maximum was 44\% in both 2006 and 2013 (Figure 1).

Females had a higher frequency of neoplasms $(p<0.01)$, mounting up to close to $65 \%$ of all evaluated cases (Figure 2a). An association between sex and histogenesis was noted, with a higher frequency of occurrence of epithelial neoplasms in females $(79.9 \%, p<0.001)$ (Figure 2b). However, there was no apparent association between sex and malignant behavior ( $p>0.05, \mathrm{OR}=1.21$ [IC 95\% 0.78-1.85]).

The mean age for neoplasm presentation in cats was $9.8 \pm 4.2$ years, with a mean of $10.1 \pm 4.1$ years for benign and $9.7 \pm 4.2$ years for malignant tumors. Figure 3 shows the frequency of presentation of tumor histotype according to age. Data indicate that hematopoietic and lymphoreticular tumors appear earlier than other types of tumors (7.8 years vs 9.6 to 11.4 years respectively, $p<0.001$ ). A X test supported an increased risk of younger cats to develop lymphoma (mean age 7.8 years, $p=0.001$ )

When age was categorized, a higher frequency of neoplasm presentation was seen for mature and senior cats, encompassing more than $65 \%$ of all tumor cases. The prime group followed with $14.8 \%$ of cases, and the geriatric and junior groups trailing with $12.2 \%$ and $5.4 \%$ respectively. Finally, kittens were affected in less than $1 \%$ of cases. No association between age group and biological behavior of tumors was found $(p=0.59)$.

The predominant tissue of origin for diagnosed tumors was epithelial, making up $56 \%$ of cases, followed by mesenchymal neoplasms (26\%) and hematopoietic and lymphoreticular with a $17 \%$ frequency of presentation each (Figure 4). Close to $85 \%$ of caseswere malignantneoplasms, which were prevalentfor all cellularlineages (Table1). 


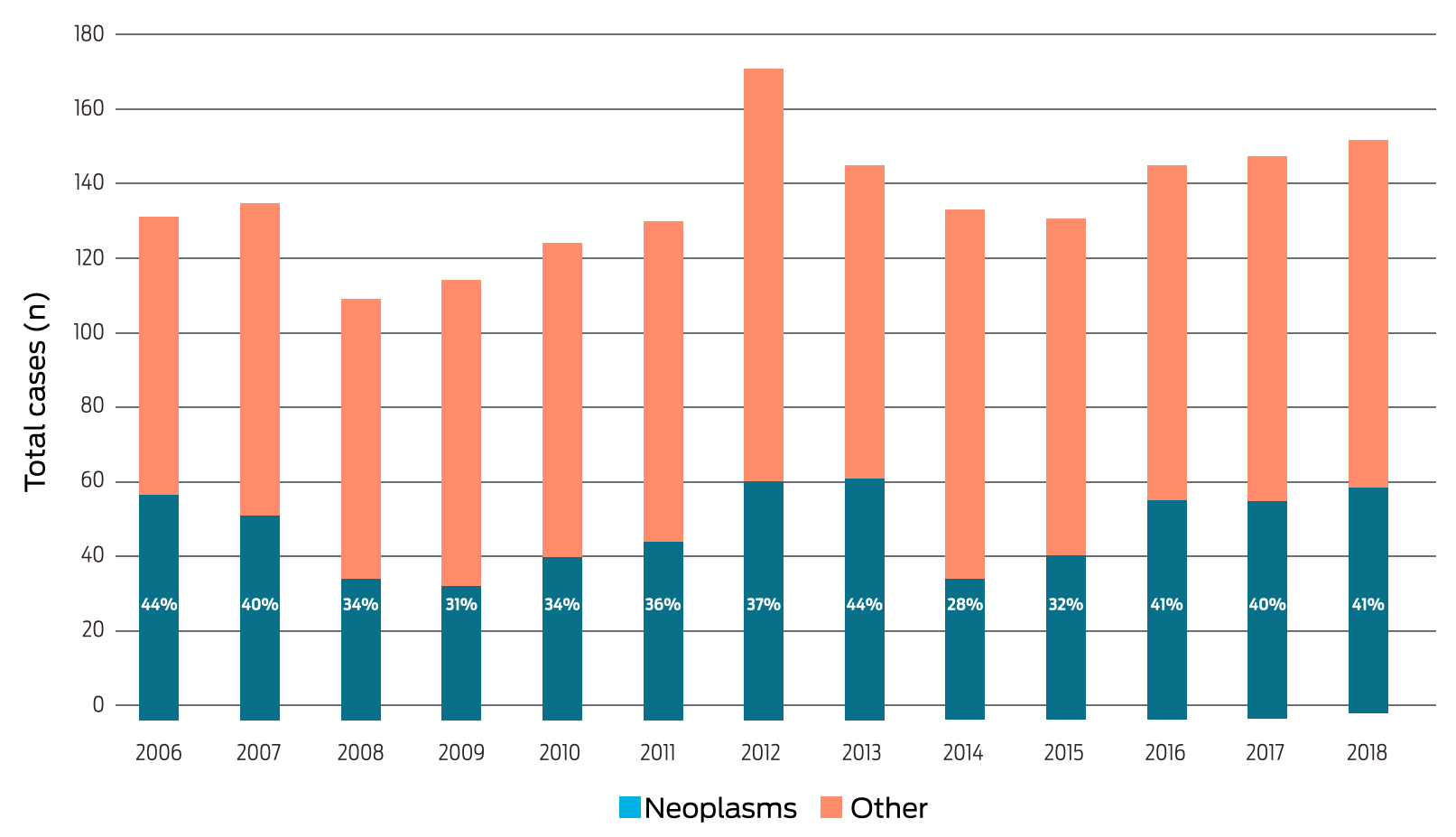

Figure 1. Number of samples submitted for histopathological evaluation at the FMVZ-UNAM Pathology Department between 2006 and 2018, and relative frequency of tumor occurrence.
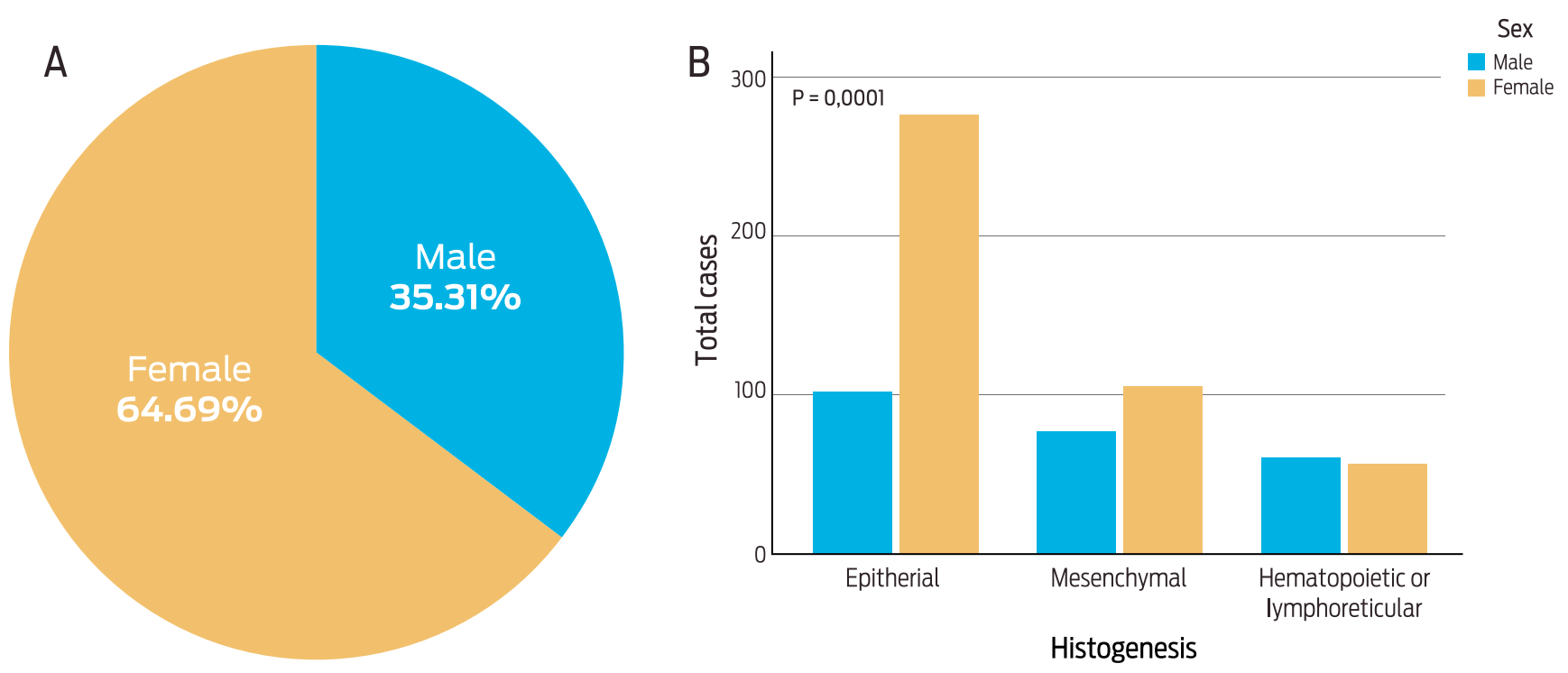

Figure 2. Distribution of neoplasms according to sex. A) Proportion of neoplasms in females and males. B) Distribution of cell lineage by sex. 


\section{Tissue of origin}
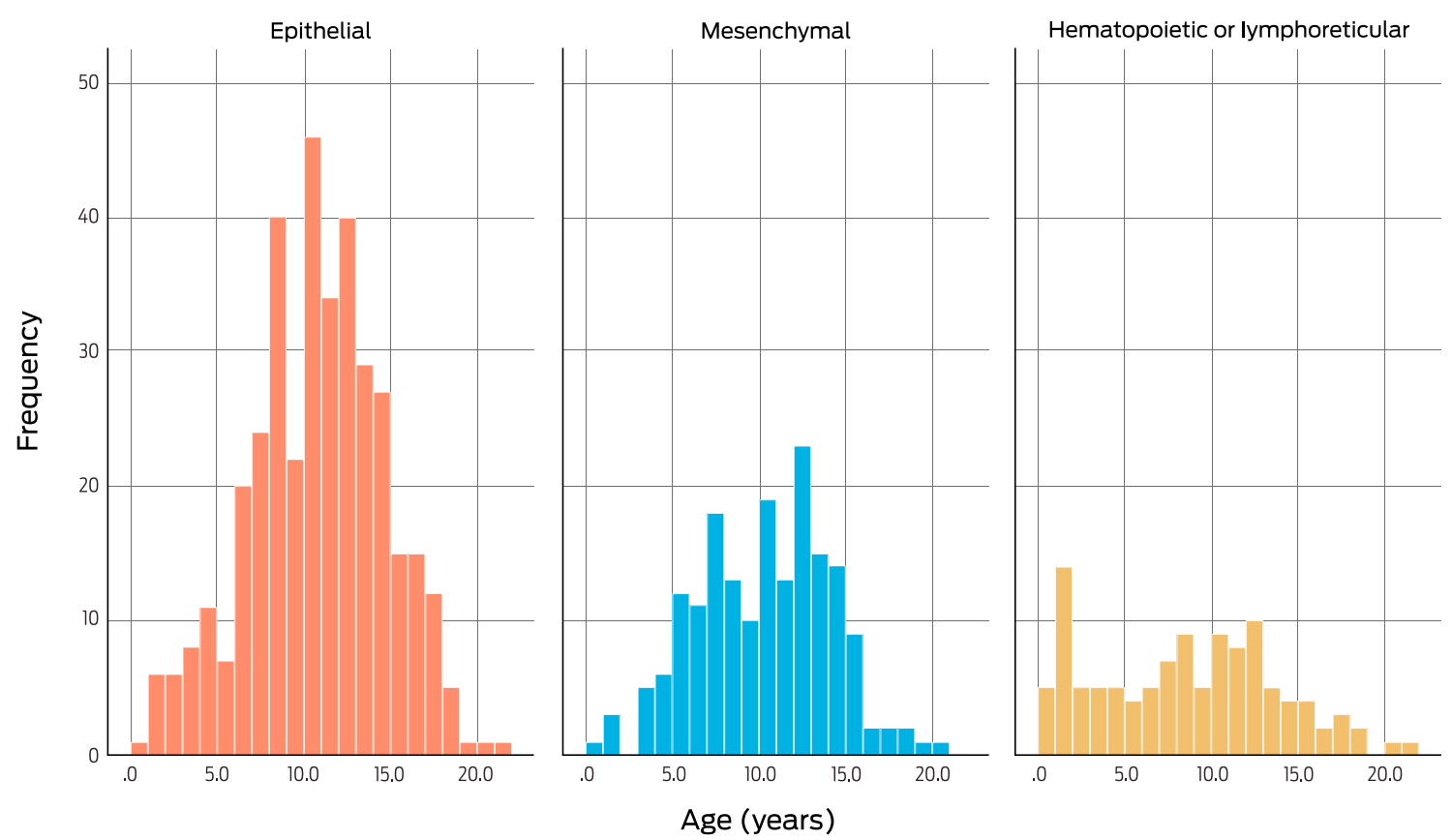

Figure 3. Frequency of tumor type (histogenesis) according to age of cats.

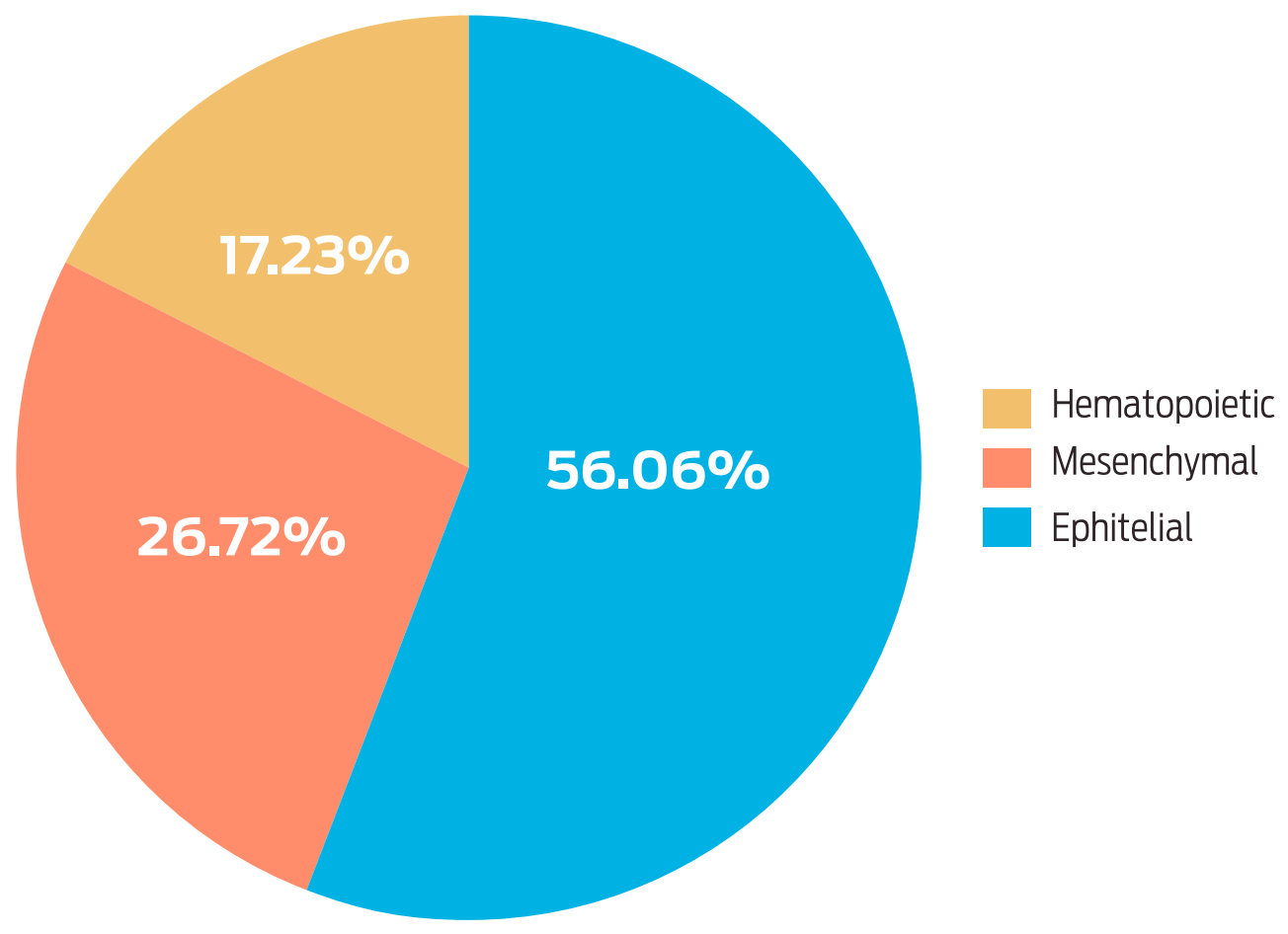

Figure 4. Distribution of neoplasms in cats according to the cellular lineage of origin. 
Table 1. Number and frequency of tumors according to cellular lineage and neoplastic behavior.

\begin{tabular}{|c|c|c|c|c|c|}
\hline & \multicolumn{3}{|c|}{ Neoplastic behavior } \\
\hline & & & Benign & Malignant & p-value \\
\hline \multirow{8}{*}{ Cellular lineage } & \multirow{2}{*}{ Epithelial } & Count & 73 & 311 & \\
\hline & & Proportion & 0.19 & 0.81 & $3.4054 \mathrm{E}-36$ \\
\hline & \multirow{2}{*}{ Mesenchymal } & Count & 27 & 156 & \\
\hline & & Proportion & 0.15 & 0.85 & $1.5721 \mathrm{E}-13$ \\
\hline & \multirow{2}{*}{$\begin{array}{l}\text { hematopoietic/ } \\
\text { lymphoreticular }\end{array}$} & Count & 5 & 113 & \\
\hline & & Proportion & 0.04 & 0.96 & $1.053 \mathrm{E}-27$ \\
\hline & \multirow[t]{2}{*}{ Total } & Count & 105 & 580 & \\
\hline & & Proportion & 0.15 & 0.85 & \\
\hline
\end{tabular}

Statistical differences $(p<0.05)$ between neoplastic behavior within cellular lineage are marked in bold.

The most frequent histotype was carcinoma, which comprised $30.5 \%$ of all cases, followed by sarcoma (13.7\%), adenocarcinoma (13.1\%), lymphoma (12.8\%), and adenoma (5.8\%) (Table 2). Figure 5 shows representative hematoxylin-eosin stained slides used for histological classification of neoplasms. Overall, the most common neoplasm was squamous cell carcinoma with a total of 117 cases or 56\% of carcinomas and 17\% of all analyzed neoplasms, followed by lymphoma with 88 cases $(12.8 \%)$, and spindle cell sarcoma with 56 cases $(9.2 \%)$. Of all adenocarcinomas, $80 \%$ were in the mammary gland, with the tubulopapillary form representing the majority of cases (50\%), followed by the tubular form (approximately $30 \%$ ). Due to this high proportion of mammary neoplasms, a sex-bias was observed with adenocarcinomas prevailing in female cats $(p<0.01)$ (Figure 6).

Lymphomas were also classified according to their anatomical region of origin, with the gastrointestinal (alimentary) presentation being the most frequent (40\%), followed closely by the multicentric form (32\%), while other types were significantly less represented (Figure 7). Three of the multicentric lymphomas presented bone marrow invasion and secondary leukemia. The age group was significantly different between anatomical origin categories, with mediastinal lymphoma being the most frequent in younger cats $(p=0.0001)$ and alimentary lymphoma in older cats (Table 3). The extranodal types of lymphoma represented only $16 \%$ of lymphoma cases $(2.4 \%$ hepatic [ $n=2], 5.9 \%$ renal $[n=5], 5.9 \%$ cutaneous $[n=5]$, pulmonary $1.1 \%[n=1]$, and splenic $1.1 \%[n=1])$. Finally, the most frequent adenomas were those with tubulopapillary presentation, complex adenoma, and papillary adenoma (11\% each).

\section{Discussion}

Cancer is a prominent disease in companion animals and one of the leading causes of pet mortality. ${ }^{13}$ Classification of neoplasms based on tissue and cellular origin, in addition to the association between frequency of presentation and demographic characteristics, can contribute to guide diagnostic and therapeutic options in veterinary clinics. In the domestic cat cohort included in this study, neoplasms rep- 
Table 2. Cellular origin, number of cases, frequency and age of presentation, of the five predominant neoplasms in cats.

\begin{tabular}{|l|l|r|l|l|l|}
\multicolumn{1}{c|}{ Neoplasm } & Histogenesis & Cases & \multicolumn{1}{c|}{ Occurrence } & Median Age (range) & Mean age (SD) \\
\hline Carcinoma & Epithelial & 209 & $30.50 \%$ & $10.0(<1-21)$ & $10.0(3.9)$ \\
\hline Sarcoma & Mesenchymal & 94 & $13.70 \%$ & $10.0(1-18)$ & $9.6(3.4)$ \\
\hline Adenocarcinoma & Epithelial & 90 & $13.10 \%$ & $11.0(1-26)$ & $10.8(3.7)$ \\
\hline Lymphoma & Hematopoietic & 88 & $12.80 \%$ & $8.0(<1-21)$ & $7.8(5.2)^{*}$ \\
\hline Adenoma & Epithelial & 40 & $5.80 \%$ & $11.0(4-18)$ & $11.4(3.3)$
\end{tabular}

* Significant difference between histotypes $(p=0.001) . S D=$ standard deviation

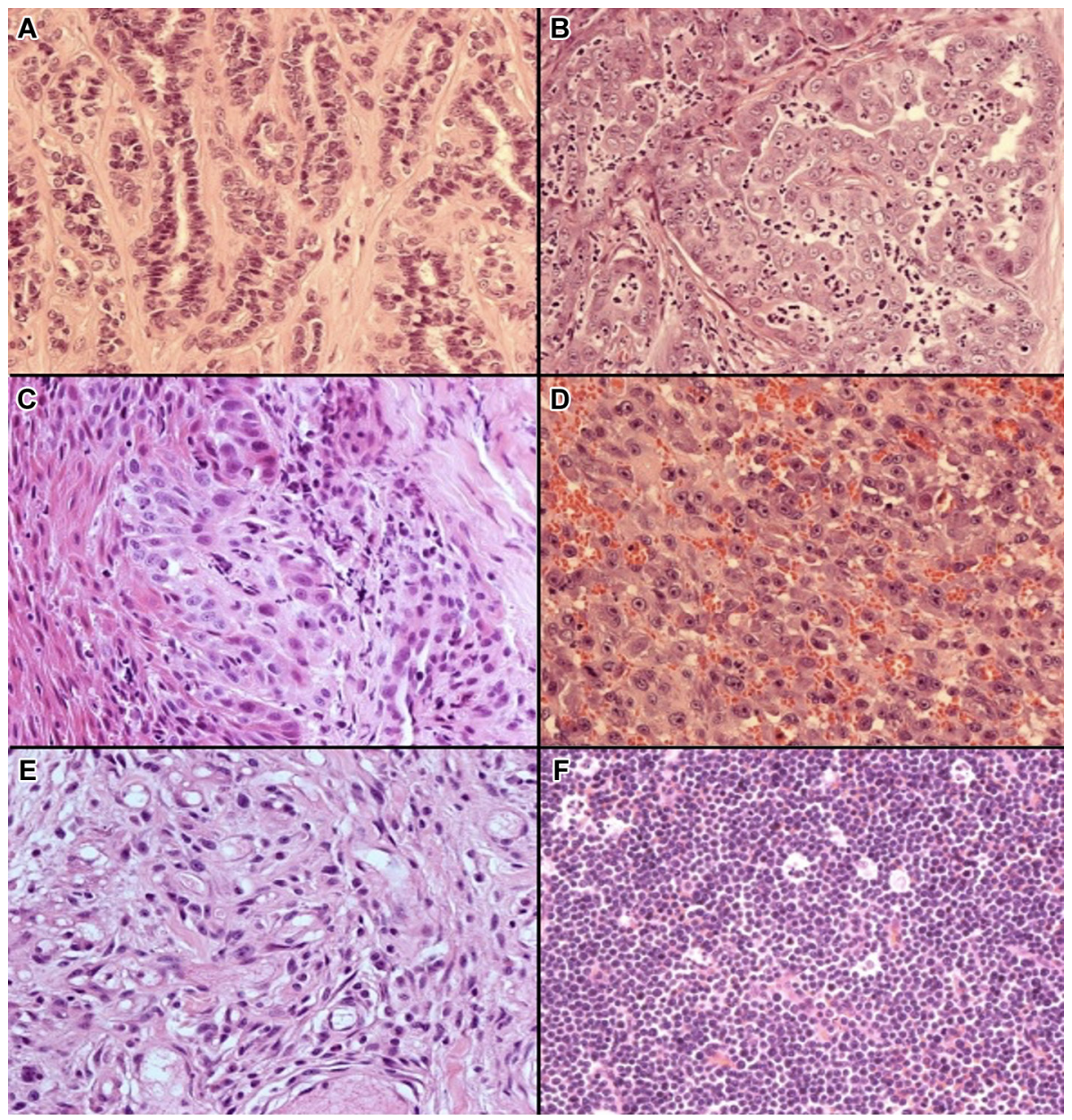

Figure 5. Histopathological features of the most frequently observed neoplasms. A) Mammary adenoma. Regular cords lined by one or two layers of epithelial cells and separated by a fine fibrovascular stroma. Neoplastic cells are cuboidal with poor cytoplasm and minimal atypia. B) Tubular carcinoma. Tubules lined by cuboidal epithelium with large, vesicular nuclei with a prominent nucleolus. There is a discrete intratubular neutrophilic infiltrate. C) Squamous cell carcinoma. Nest of cells with abundant eosinophilic cytoplasm with distinct borders and large vesicular nuclei with a single prominent nucleolus. These cells are immersed in desmoplastic tissue. D) Hemangiosarcoma. Polygonal cells surrounding discrete vascular channels, showing prominent nucleoli and numerous mitoses. E) Soft tissue sarcoma. Spindle-shaped tumor cells, with moderate eosinophilic cytoplasm, poorly defined; the nuclei are oval, with granular chromatin and prominent nucleoli. F) Mediastinal lymphoma. Monomorphic neoplastic lymphoid cells arranged in a solid mantle, supported by a scarce fibrovascular stroma. The cells have scarce cytoplasm, oval nuclei with finely granular chromatin, evident nucleoli, and frequent atypical mitoses. There are multifocal areas of necrosis. 


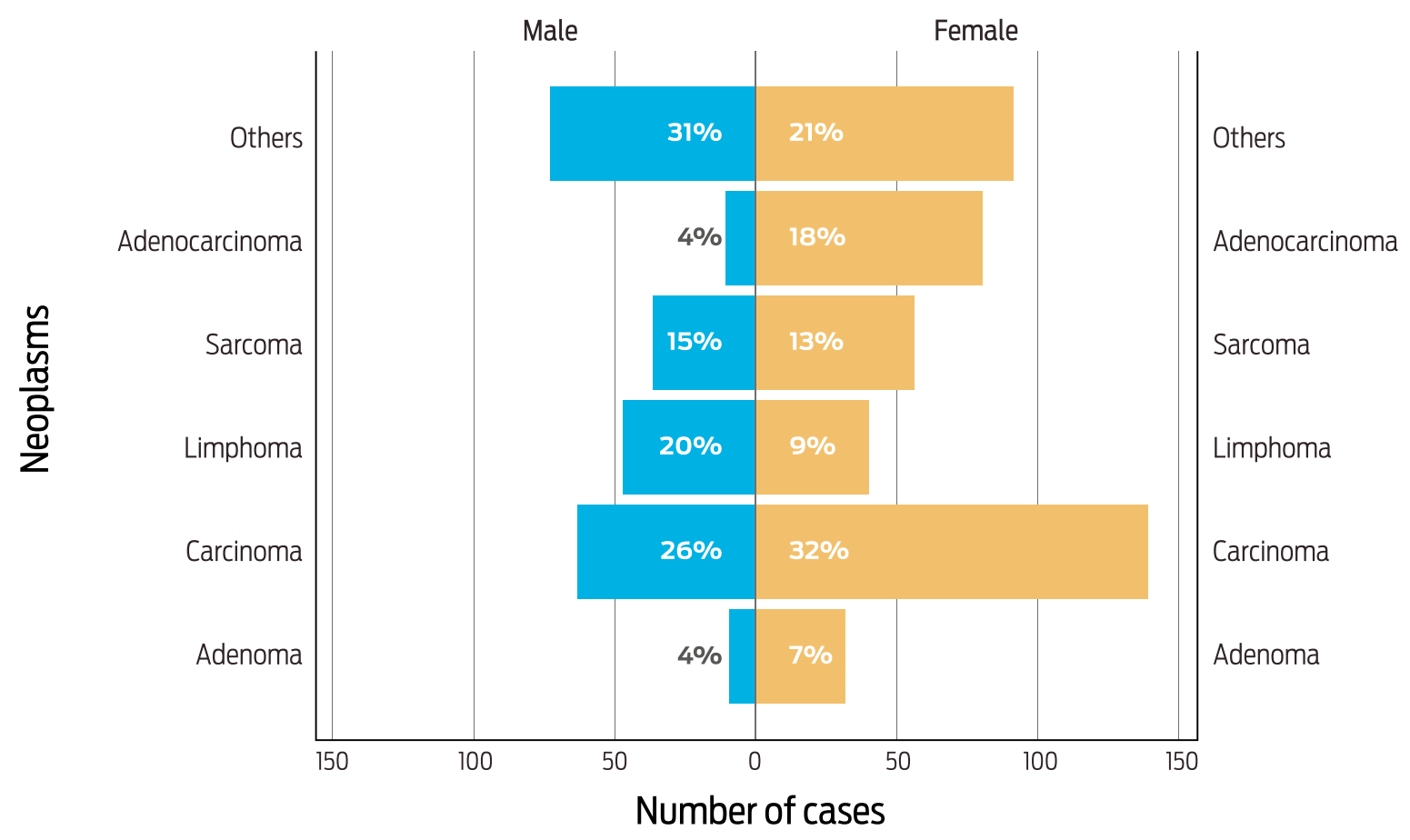

Figure 6. Most frequent neoplasm histotype distribution by sex.

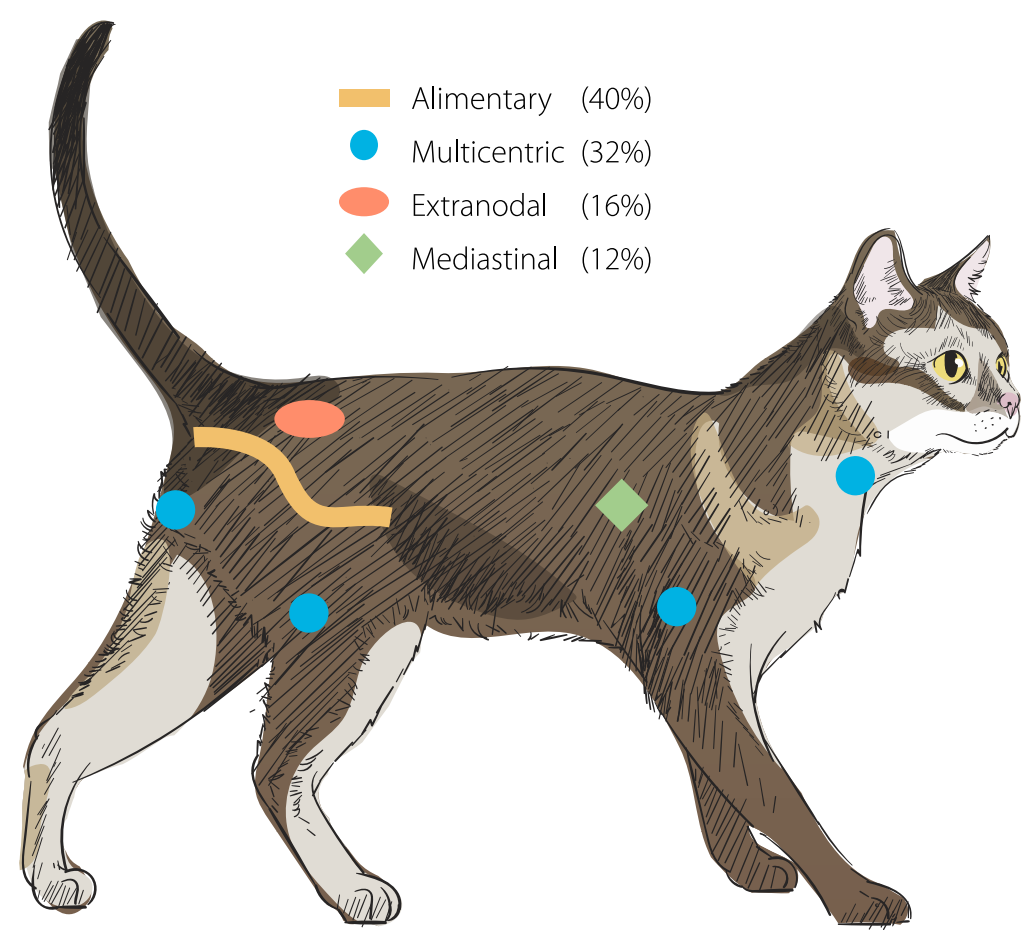

Figure 7. Anatomic localization and frequency of presentation of feline lymphoma. 
Table 3. Distribution of lymphoma by anatomical location and age of cats.

\begin{tabular}{|c|c|c|c|c|c|c|}
\hline Anatomical location & \multicolumn{3}{|c|}{ Frequency } & \multicolumn{4}{|c|}{ Age (years) } \\
\hline & $\mathrm{n}$ & $\%$ & Mean & SD & Min & Max \\
\hline Alimentary & 34 & $40 \%$ & 10.0 & 3.88 & 0.3 & 17.0 \\
\hline Multicentric & 28 & $32 \%$ & 6.5 & 6.0 & 0.3 & 20.0 \\
\hline Mediastinal & 9 & $12 \%$ & 2.2 & 2.0 & 0.5 & 7.0 \\
\hline Extranodal & 14 & $16 \%$ & 6.8 & 5.3 & 3.0 & 16.0 \\
\hline Total & 85 & $100 \%$ & & & \\
\hline
\end{tabular}

SD: standard deviation; Min: minimum; Max: maximum.

resented $37.7 \%$ of all referred histopathological cases. The predominant tumor histogenesis was epithelial, followed by mesenchymal and lymphoreticular, similar to results from cat groups studied by Graf et al in Switzerland, ${ }^{3}$ and by Zambelli et $a l$ in South Africa. ${ }^{14} \mathrm{~A}$ predominance of malignant behavior was found in this study for tumors of all tissues of origin (Table 2). However, no differences in malignancy were observed when considering mean age of presentation. This result paralleled the report by Manuali et al in a shorthair cat population in Italy. ${ }^{15}$ In addition, a higher frequency of cancer was observed in females than in males $(p<0.001)$, coinciding with previous reports. ${ }^{13,16}$ The overall similar outcomes from these studies indicate that regional discrepancies between histogenesis, age of presentation, and sex-bias are limited.

Squamous cell carcinoma was the most common neoplasm in cats from this work, making up $17 \%$ of cases ( $n=117)$, a result that is comparable to that found in other studies. ${ }^{14,17-19}$ Manuali et al. found this histotype as the most common malignancy among skin (28.8\%), oral cavity and tongue tumors (46\%). ${ }^{15}$ Other studies in cats focusing on cutaneous neoplasms in the head, neck and oral mucosa also found a predominant presentation of this histotype., $7,20-22$ Nonetheless, when all anatomical regions are considered, this predominance can change, since Graf et al noted in a Swiss feline cancer registry from 1965 to 2008, that this type of tumor placed fourth with just $9.9 \%$ of all cases, below adenomas/adenocarcinoma (19.1\%), fibroma/fibrosarcoma (18.4\%) and lymphoma (15.6\%) $)^{5}$. The most common age of presentation for squamous cell carcinoma in this study was 7-10 years (mature cats), deviating slightly from previous reports describing an older age of occurrence (11-14 years). 7,17,18,23 The frequency of squamous cell carcinoma in older cats was half of that observed for mature cats in this study. Since this type of neoplasm is strongly related to sunlight exposure, ${ }_{r}^{17,18}$ we can speculate than the lifestyle and the outdoor habits in the studied cat population could be a reason for the high occurrence and early presentation of this type of tumor, contrary to the largely indoor cat populations found in other countries. Indeed, the low prevalence of squamous cell carcinoma reported in the Graf et al study ${ }^{23}$ could be associated 
with differences in temperature and sunlight exposure between Mexico and Switzerland. On the other hand, Zimbelli et al also found this neoplasm to be highly represented in South African cats correlating with a greater ultraviolet light exposure. ${ }^{14}$.

Adenocarcinomas are frequently reported in female cats because of the high incidence of mammary gland neoplasms. ${ }^{24}$ The range of incidence varies according to geographic regions, which also relates to spay practices and age at the time of surgery. ${ }^{25}$ These neoplasms are generally aggressive and have a poor prognosis. ${ }^{26}$ In this study, adenocarcinomas were the second most common tumor in female cats, representing $18.3 \%$ of cases, of which close to $80 \%$ were of mammary origin. This is in agreement with the study of Graf et al, that places mammary carcinoma as the most frequent neoplasm, comprising $19.1 \%$ of the cases and a higher odds ratio in female cats. ${ }^{23}$ Moreover, Morris et al found mammary carcinomas to place just below lymphoma and skin tumors, accounting for $17 \%$ of cases. ${ }^{24}$ The reported age of presentation for mammary carcinomas ranges between 10 and 12 years, 27,28 while it varied between 7 and 14 years of age in our study. In male cats, mammary tumors make up for $1-5 \%$ of cases; ${ }^{24}$ the $1.4 \%$ observed in our study falls directly into this range. There are studies that relate incidence of mammary tumors to neutering practices, ${ }^{24}$ unfortunately, our study lacks data concerning reproductive status (intact vs. spayed), as most records did not include this information.

Another important neoplasm found in this study was lymphoma. Lymphoma has been reported as the most common neoplasm in cats; ${ }^{29}$ however, according to this and other studies, $1,3,4,14,15,23$ epithelial neoplasms are more prevalent. Nevertheless, a significant incidence of lymphoma in cats from this study can still be appreciated, particularly in young cats. Lymphoma represents a diverse group of lesions that vary in terms of cell type, grade of dissemination, and anatomic localization. ${ }^{30}$ To understand its behavior and establish prognostic factors, a variety of classifications need to be made taking into account morphologic criteria, immunophenotyping, and more recently genotyping, a practice mainly adopted from human medicine and applied to veterinary cases. ${ }^{31}$ At present, the most common classification for lymphoma developed by a panel of experts from the World Health Organization (WHO), attempts to standardize its nomenclature and correlate it with the prognosis. 5,25,29,31-34 Alimentary (40\%) and multicentric (33\%) lymphomas were the predominant types of lymphoma in this study. These two types are consistently reported as the most frequent lymphomas in cats around the world. ${ }^{15,29,31,34-36}$ One exception is the study by Wolfesberger et al, ${ }^{26}$ where alimentary lymphoma was also found to be the most common presentation, but there was no report of multicentric lymphoma in their 30-case revision. In fact, extranodal lymphoma was the second most common form in their study, contrary to our findings where this type of tumor was found in only $16 \%$ of lymphoma cases. In Brazil, studies confirmed an important presence of multicentric and/or mediastinal lymphoma in cats, with a correlation with the prevalence of feline leukemia virus (FeLV). ${ }^{37,38}$ Since data regarding the prevalence of this viral pathogen in Mexico is limited, FeLV cannot be discarded as a potential cause of the high frequency of mediastinal and multicentric cases reported in this study. The mean age of presentation of lymphoma was $7.8 \pm 5.2$ years, similar to that observed by Graf et al who found this neoplasm to be the most frequent tumor type in young cats. ${ }^{23}$ 
A relationship between age of presentation and anatomical site was also found in this study, with mediastinal, multicentric and extranodal locations being particularly frequent in junior and prime cats. These results are in accordance with previous reports. ${ }^{36,39}$ Interestingly, during the period comprised in this study, no cases of nasal or ocular lymphomas were diagnosed, despite their relatively regular observation in other North American studies.

\section{Conclusions}

Cancer registries in veterinary centers allow a better understanding of the epidemiological characteristics of different neoplasms, and point out discrepancies that may occur between regions, which can support better diagnosis and treatment. This study shows that cancer is a significant health problem of domestic cats from central Mexico City, which could reflect the situation throughout the city and possibly the country. Squamous cell carcinoma was identified as the most frequent neoplasm, with an earlier age of presentation than previously reported. This may be related to both the lifestyle of cats in the region and significant exposure to solar radiation. Epithelial neoplasms were more common in females than in males, with adenocarcinomas in the mammary gland as the most prevalent type; further studies should evaluate an association with neutering practices in our country. Lymphoma was also highly represented in the studied cat cohort, particularly alimentary lymphoma, just as in other studies throughout the world. Nevertheless, other less-reported presentations, such as multicentric lymphoma, were also observed, which may be associated with FeLV prevalence in Mexico. The compiled data in this study serves as a foundation for future research on specific neoplasms known to have a significant presence in cat populations. 


\section{Acknowledgements}

The authors also gratefully acknowledge Eugenio Córdova López, Academic Technician of the FMVZ Department of Pathology, for his support with the microscopic photographs.

The authors thank Dr. José Luis Pablos Hach, professor at the Faculty of Veterinary Medicine and Zootechnics of the National Autonomous University of Mexico, for his valuable advice in the statistical analysis of the data.

\section{References}

1. Schmidt JM, North SM, Freeman KP, Ramiro Ibañez F. Feline pediatric oncology: retrospective assessment of 233 tumors from cats up to one year (1993 to 2008). J Small Anim Pract. 2010; 51(6):306-11. DOI: 10.1111/j.1748-5827.2010.00915.x

2. Brønden $L B$, Flagstad $A$, Kristensen AT. Veterinary cancer registries in companion animal cancer: a review. Vet Comp Oncol. 2007;5(3):133-44.

3. Graf $R$, Grüntzig $K$, Hässig $M$, Axhausen KW, Fabrikant $S$, Welle $M$, et al. Swiss Feline Cancer Registry: A Retrospective Study of the Occurrence of Tumours in Cats in Switzerland from 1965 to 2008. J Comp Pathol. 2015;153(4):266-77. DOI: 10.1016/j.jcpa.2015.08.007

4. Vascellari M, Baioni E, Ru G, Carminato A, Mutinelli F. Animal tumor registry of two provinces in northern Italy: incidence of spontaneous tumors in dogs and cats. BMC Vet Res. 2009;5(1):39. DOI: 10.1186/1746-6148-5-39

5. Butler ML, et al. Epidemiology and the evidence-based medicine approach. In Withrow SJ, Vail DM, Page RL, eds. Withrow \& MacEwen's small animal clinical oncology. 5th ed. St. Louis, MO: Elsevier; 2013. p. 68-82.

6. Dorn CR. The epidemiology of cancer in animals. California Medicine. 1967;107:481-9.

7. Ho NT, Smith KC, Dobromylskyj MJ. Retrospective study of more than 9000 feline cutaneous tumors in the UK: 2006-2013. J Feline Med Surg. 2018;20(2):12834. DOI: $10.1177 / 1098612 \times 17699477$

8. Kamstock DA, Russell DS, Powers BE. In Vail DM, Thamm DH, Liptak JM. eds. Withrow and MacEwen's small animal clinical oncology. 6th ed. Maryland Heights: Elsevier; 2019.

9. Van Belle G, Fisher L, editors. Biostatistics: a methodology for the health sciences. 2nd ed. Hoboken, NJ: John Wiley \& Sons; 2004.

10. Hollander $\mathrm{M}$, et al. Nonparametric statistical methods. 3rd ed. Hoboken, NJ: John Wiley \& Sons, Inc, 2014.

11. Kuehl RO. Design of experiments: statistical principles of research design and analysis. Duxbury/Thomson Learning; 2000.

12. Vogt A, Rodan I, Brown M, Brown S. AAFP - AAHA Feline Life Stage Guidelines. J Am Anim Hosp Assoc. 2010;46:70-85.

13. Vascellari M, Baioni E, Ru G, Carminato A, Mutinelli F. Animal tumour registry of two provinces in northern Italy: incidence of spontaneous tumours in dogs and cats. BMC Vet Res. 2009;5(1):39.

14. Zambelli A. Feline Cancer Prevalence in South Africa (1998 - 2005): Contrasts with the Rest of the World. J Basic Appl Sci. 2015;11:370-80. 
15. Manuali E, Forte C, Vichi G, Genovese DA, Mancini D, De Leo AAP, et al. Tumours in European Shorthair cats: a retrospective study of 680 cases. J Feline Med Surg. 2020;22(12):1095-1 102. doi: 1098612X2090503.

16. Patnaik AK, Liu SK, Hurvitz Al, McClelland AJ. Nonhematopoietic neoplasms in cats. JNCI. 1975;54(4):855-60. https://doi.org/10.1093/jnci/54.4.855

17. Lino $M$, Lanore $D$, Lajoinie $M$, Jimenez $A$, Crouzet $F$, Queiroga FL. Prognostic factors for cats with squamous cell carcinoma of the nasal planum following high-dose-rate brachytherapy. J Feline Med Surg. 2019;21(12):1157-64.

18. Murphy S. Cutaneous squamous cell carcinoma in the cat: Current understanding and treatment approaches. J Feline Med Surg. 2013;15(5):401-7.

19. Blackwood L. Cats with cancer: Where to start. J Feline Med Surg. 2013;15(5):366-77.

20. Olmsted GA, Farrelli J, Post GS, Smith J. Tolerability of toceranib phosphate (Palladia) when used in conjunction with other therapies in 35 cats with feline oral squamous cell carcinoma: 2009-2013. J Feline Med Surg. 2017;19(6):56875. DOI: $10.1177 / 1098612 \times 16638118$

21. Stebbins KE, Morse CC, Goldschmidt MH. Feline oral neoplasia: A ten-year survey. Vet Pathol 1989;26(2):121-8.

22. Tannehill-Gregg SH, Levine AL, Rosol TJ. Feline head and neck squamous cell carcinoma: a natural model for the human disease and development of a mouse model. Vet Comp Oncol 2006;4(2):84-97.

23. Graf R, Grüntzig K, Boo G, Hässig M, Axhausen KW, Fabrikant $S$, et al. Swiss Feline Cancer Registry 1965-2008: the influence of sex, breed, and age on tumour types and tumour locations. J Comp Pathol. 2016;154(2-3):195-210. DOI: 10.1016/j.jcpa.2016.01.008

24. Morris J.Mammary tumours in the cat:Size matters, so early intervention saves lives. J Feline Med Surg. 2013;15(5):391-400. DOI: 10.1177/1098612X13483237

25. Goldschmidt HM, et al. Tumors in the mammary gland. In Meuten DJ, ed. Tumors in domestic animals. 5th ed. Ames, lowa: Wiley/Blackwell; 2017. p. 723-65.

26. Zappulli $V$, et al. Proposed classification of the feline "complex" mammary tumors as ductal and intraductal papillary mammary tumors. Vet Pathol. 2013;50(6):1070-7. DOI: 10.1177/0300985813488894

27. Misdorp W. Tumors of the mammary gland. In: Meuten DJ, ed. Tumors in domestic animals. Oxford: Blackwell; 2002. p. 575-606.

28. Lana SE, Rutteman GR, Withrow S. Feline mammary tumors. In: Withrow SJ, Vail DM, eds. Small animal clinical oncology. 4th ed. St Louis, MO: Elsevier; 2007. p. 628-36.

29. Wolfesberger B, Fuchs-Baumgartinger A, Greß V, Hammer SE, Gradner $G$, Knödl $K$, et al. World Health Organisation Classification of lymphoid tumours in veterinary and human medicine: A comparative evaluation of gastrointestinal lymphomas in 61 cats. J Comp Pathol. 2018;159:1-10. DOI: 10.1016/j. jcpa.2017.12.006

30. Kiselow MA, Rassnick KM, McDonough SP, Goldstein RE, Simpson KW, Weinkle TK, et al. Outcome of cats with low-grade lymphocytic lymphoma: 41 cases (1995-2005). J Am Vet Med Assoc. 2008;232(3):405-10. 
31. Vezzali E, Parodi AL, Marcato PS, Bettini G. Histopathologic classification of 171 cases of canine and feline non-Hodgkin lymphoma according to the WHO. Vet Comp Oncol 2010;8(1):38-49. DOI: 10.1111/j.1476-5829.2009.00201.x

32. Valli VE, et al. Hematopoietic system Jubb. In Maxie MG, ed. Kennedy, and Palmer's pathology of domestic animals. 6th ed. Vol. 3. St. Louis, MO: Elsevier; 2016. p. 213-42.

33. Valli VE. Veterinary comparative hematopathology. 1st ed. Ames, lowa: Blackwell; 2007.

34. Wolfesberger B, Skor O, Hammer SE, Flickinger I, Kleiter M, Rütgen BC, et al. Does categorization of lymphoma subtypes according to the World Health Organization classification predict clinical outcome in cats? J Feline Med Surg. 2017;19(8):897-906. DOI: 10.1177/1098612X16666119

35. Louwerens $M$, London CA, Pedersen NC Lyons LA. Feline lymphoma in the post-Feline leukemia virus era. J Vet Intern Med. 2005;19:329-35.

36. Morris J, Dobson JM. Small animal oncology. London; Malden, MA: Blackwell Science; 2001.

37. Cristo TG, Biezus G, Noronha LF, Pereira LHHS, Withoeft JA, Furlan LV, et al. Feline lymphoma and a high correlation with feline leukaemia virus infection in Brazil. J Comp Pathol. 2019;166:20-8.

38. Leite-Filho RV, Panziera W, Bandinelli MB, Henker LC, da Conceição Monteiro K, Corbellini LG, et al. Epidemiological, pathological and immunohistochemical aspects of 125 cases of feline lymphoma in Southern Brazil. Vet Comp Oncol. 2019;1-7.

39. Vail DM, Moore AS Ogilvie GK, Volk LM. Feline lymphoma (145 cases): Proliferation indices, cluster of differentiation 3 immunoreactivity, and their association with prognosis in 90 cats. J Vet Intern Med. 1998;12(5):349-54. DOI: 10.1111/j.1939-1676.1998.tb02134.x 